\section{LEOPARD FROG AT BOMPAS LAKE, SASKATCHEWAN}

STUART HEARD, Lakeland College, Vermilion, Alberta. TOB $4 \mathrm{MO}$

On the portage from Black Lake to Bompas Lake in northern Saskatchewan $\left(59^{\circ} 40^{\prime} \mathrm{N}, 105^{\circ} \mathrm{W}\right)$, along the border of a small, open-water muskeg, a quick movement in the water attracted attention. Closer investigation disclosed a large Leopard Frog (Rana pipiens) swimming through the sedges. I was able to catch the frog and David Henry and I examined it closely.

It was an adult Leopard Frog, approximately 3 in. long, an overall green color, spotted with darker green, yellow-margined spots. The overall appearance closely matched the description given by Mary Dickerson, ${ }^{2}$ including pointed head, relatively slender body, yellowish lateral folds, and yellowish to white underparts. The large size, distinct spots, and lack of a dark band running through the eye identified the specimen as a Leopard Frog rather than Wood Frog. The frog was released where it was found, 15 August 1983. No photographs were taken.
Later, on the same portage a second Leopard Frog was seen, though not examined in hand.

The Leopard Frog has been recorded north of Lake Athabasca but was thought to be absent from the extreme northeast section of the province. ${ }^{1}$ This sighting is evidence of the extended range of this amphibian since Bompas Lake is situated just east of extreme north-central Saskatchewan, some 30 miles from the Northwest Territories boundary. This sighting thus represents a modest northeastward range extension for the Leopard Frog in Saskatchewan. Stebbins ${ }^{1}$ describes the Leopard Frog's distribution including the District of Mackenzie and the Great Slave Lake region ${ }^{3}$. This sighting is considerably east and south of his range identification. Perhaps further investigation of the range of this frog may prove subarctic distribution throughout Canada.

'COOK, F.R. 1977. A guide to the amphibians and reptiles of Saskatchewan. Department of Youth and Culture, Regina. $40 \mathrm{pp}$

${ }^{2}$ DICKERSON, M.C. 1969. The frog book. Dover Publ. New York. 253 pp

${ }^{3}$ STEBBINS, R.C. 1966. A field guide to western reptiles and amphibians. Houghton Mifflin Co., Boston. 279 pp

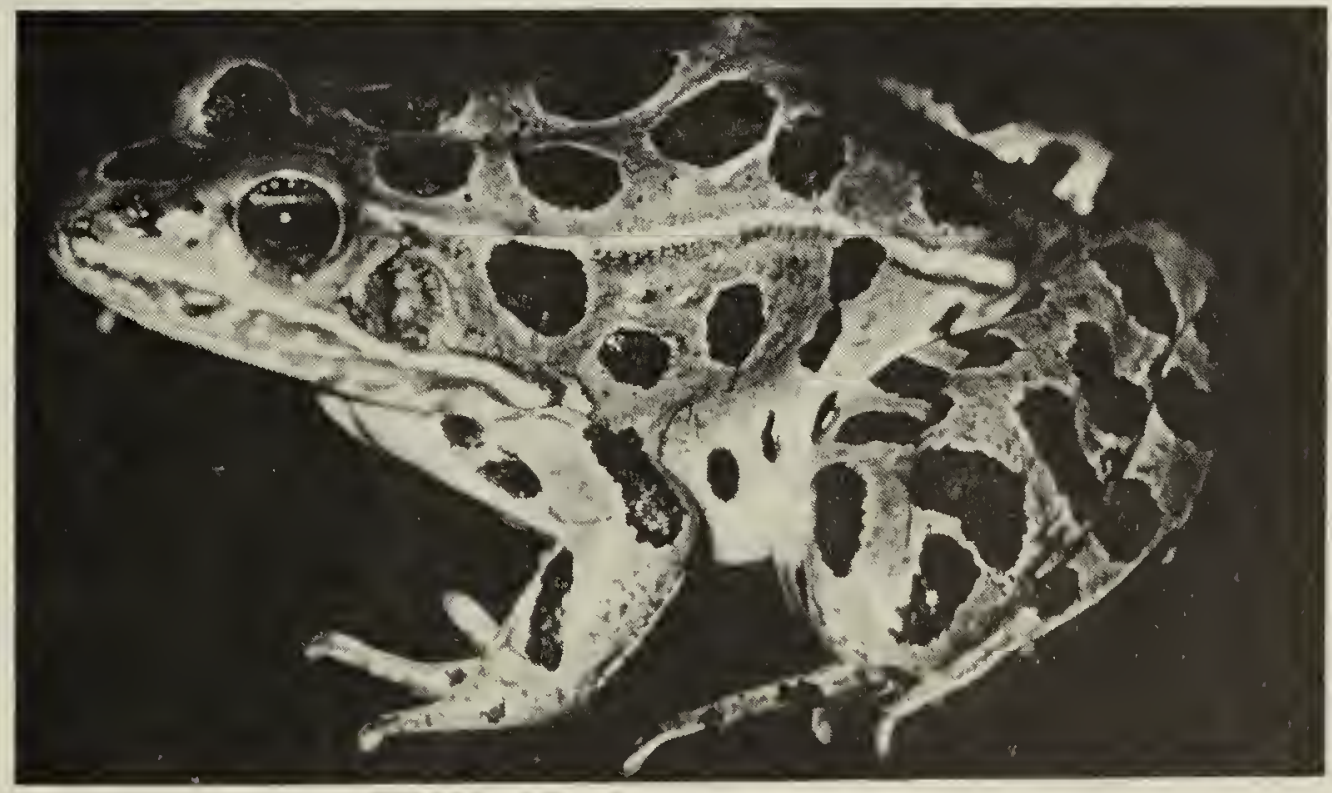

Leopard Frog

W.B. Preston 